\title{
SEAS exercises revert progression of adult scoliosis: a retrospective long-term study
}

\author{
Alessandra Negrini, Stefano Negrini, Silvana Parzini, Michele Romano*, \\ Fabio Zaina and Salvatore Atanasio
}

Address: ISICO (Italian Scientific Spine Institute), Milan, Italy

* Corresponding author

\author{
from $5^{\text {th }}$ International Conference on Conservative Management of Spinal Deformities \\ Athens, Greece. 3-5 April 2008 \\ Published: 15 January 2009 \\ Scoliosis 2009, 4(Suppl I):O55 doi:I0.I|86/I748-7|6I-4-SI-O55
}

This abstract is available from: http://www.scoliosisjournal.com/content/4/SI/O55

(c) 2009 Negrini et al; licensee BioMed Central Ltd.

\section{Background}

Formal papers regarding the efficacy of exercise in adult scoliosis are few.

\section{Aim}

To verify, if the natural history of adult scoliosis can be modified by exercises.

\section{Study design}

Retrospective pre-post study.

\section{Population}

Thirty one patients ( 3 males) of $38 \pm 11$ years and $55 \pm$ $14^{\circ}$ Cobb scoliosis, treated for 3 (range 1-18) years because of progression subjectively perceived (17 patients), or objectively documented (14 patients: subgroup A, previous observation of 10 years, range 1-27), have been included. 6 patients (sub-group B) were observed also after stopping treatment for $6(3-10)$ years.

\section{Methods}

Five degress of Cobb angle was considered significant for clinical change. Statistical analysis included paired t-test, ANOVA, Kruskall-Wallis and chi-square tests.

\section{Results}

Exercises caused a statistically significant decrease of $3.6 \pm$ $5^{\circ}$ of scoliosis $\left(-3.2 \pm 4.3^{\circ}\right.$ per year): 1 patient progressed, $45 \%$ improved; in sub-group A results were identical, after a previous worsening of $9.7 \pm 6.8^{\circ}\left(+2.1 \pm 4.3^{\circ}\right.$ per year $)$; in sub-group B stopping exercises caused a progression of $8.3 \pm 3.8^{\circ}\left(+1.4 \pm 0.5^{\circ}\right.$ per year $)$. The best results were observed in patients exercising since, even if some patients continued to decrease their curve during the years.

\section{Conclusion}

SEAS exercises revert the progression of adult scoliosis, and a prospective study is already under way. The different results according to length of treatment could be due to a plateau of correction or to an increase of quality of the protocol applied (SEAS changes continuously according to new knowledge in the literature). These results question the immediate need for surgery when facing progression of deformity in adulthood.

\section{References}

I. Hawes MC: The use of exercises in the treatment of scoliosis: an evidence-based critical review of the literature. Pediatric Rehabilation 2003, 6(3-4): I7I-82.

2. Guigui P, Rillardon L: Adult spinal deformities. Rev Prat 2006, 56(7):70I-8.

3. Aebi M: The adult scoliosis. Eur Spine 2005, I4(I 0):925-48. 